\title{
DYNAMICS OF VIBRATIONAL RELAXATION OF MULTIPHOTON EXCITED SF 6 MOLECULES IN GASEOUS MIXTURES CONTAINING OZONE AND INERT GASES (He, Ar, Kr)
}

\author{
V. V. TIMOFEEV, B. S. LUNIN, N. Yu MORDKOVICH \\ and Yu. N. ZHITNEV
}

\begin{abstract}
Chair of Physical Chemistry, Chemical Department, M.V. Lomonosov State University, Moscow, Lenin Hills, V-234, USSR
\end{abstract}

(Received 9 November, 1988; in final form 16 January, 1989)

\begin{abstract}
$\mathrm{SF}_{6}$ at pressure of 0.6 Torr in gas mixtures with ozone $(0 \div 5 \mathrm{Torr})$ and inert gases: $\mathrm{He}, \mathrm{Ar}, \mathrm{Kr}(0 \div 5$ Torr) was vibrationally excited with and IR pulsed radiation of $\mathrm{CO}_{2}$ TEA laser at 10P20 laser line $(F=0.6$ $\mathrm{J} / \mathrm{cm}^{2}$ ). The vibrational energy transfer from multiphoton excited (MPE) molecules $\mathrm{SF}_{6}$ to the components of gaseous mixture was probed by $U V$ absorption of ozone at $\lambda=253.6 \mathrm{~nm}$ band. The relaxation process of MPE molecules $\mathrm{SF}_{6}$ was proposed to occur through parallel $\mathrm{V}-\mathrm{V}^{\prime}$ and $\mathrm{V}-\mathrm{T}$ collisional channels. Based on the kinetic model, collisional rate constants were determined from the time evolution of UV absorption data after laser shot. The obtained values of relaxation rate constants are: $k \mathrm{~V}_{\mathrm{V}-\mathrm{V}_{3}}^{\mathrm{S}_{\mathrm{S}}}=7.7$ $10^{-13} \mathrm{~cm}^{3} / \mathrm{s}, k_{\mathrm{V}-\mathrm{T}}^{\mathrm{SF} G \mathrm{He}}=3.110^{-13} \mathrm{~cm}^{3} / \mathrm{s}, k_{\mathrm{V}-\mathrm{T}}^{\mathrm{SF}^{-A r}}=2.310^{-13} \mathrm{~cm}^{3} / \mathrm{s}, k_{\mathrm{V}-\mathrm{T}}^{\mathrm{SF}-\mathrm{Kr}}=7.710^{-14} \mathrm{~cm}^{3} / \mathrm{s}, k_{\mathrm{V}-\mathrm{T}}^{\mathrm{SF} G \mathrm{SF}_{6}}=$ $(4.8 \div 6.4) 10^{-13} \mathrm{~cm}^{3} / \mathrm{s}$.

The observed decay of IR fluorescence from MPE SF ${ }_{6}$ molecules at $\lambda=6.3 \mu \mathrm{m}$ wave number in $\mathrm{SF}_{6}-\mathrm{Kr}$ gas mixtures had an exponential time profile with the constant characteristic relaxation time $(V-T)$. The rate of IR fluorescence quenching allowed us to find an effective $\mathrm{V}-\mathrm{T}$ relaxation rate constants for collisional partners: $k_{\mathrm{V}-\mathrm{T}}^{\mathrm{SFG}-\mathrm{Ar}}=7.810^{-14} \mathrm{~cm}^{3} / \mathrm{s} . k_{\mathrm{T}-\mathrm{V}}^{\mathrm{SFG-SF}}=1.010^{-12} \mathrm{~cm}^{3} / \mathrm{s}$.
\end{abstract}

\section{INTRODUCTION}

Description of different physical and chemical processes in gaseous media occurring in the field of intense IR radiation require quantitative data on collision relaxations of multiphoton excited (MPE) molecules. Characteristic relaxation time for the MPE molecules characterizes the energy redistribution in the system and at the same time gives practical information concerning for instance the thermalization rate of the system. The latter is essential for the estimation of the time necessary to achieve the top equilibrium temperature of the gaseous mixture in laser-powered homogeneous pyrolysis (LPHP), ${ }^{1}$ when chemical reaction initiated by pulsed IR sensitization. This method proves quite effective for the study of mechanism and kinetics of high temperature gaseous reactions especially those with participation of thermodynamically unstable compounds such as ozone.

Sulphur hexafluoride $\left(\mathrm{SF}_{6}\right)$ is known to be one of the most commonly used IR sensitizers. However, the number of studies on collision deactivation of $\mathrm{SF}_{6}$ molecules excitated by the $\mathrm{CO}_{2}$-laser is limited. ${ }^{2-11}$ For the most part they concern with the investigation $\mathrm{V}-\mathrm{T}$ relaxation process of $\mathrm{SF}_{6}$ in the absence of chemical reactions. 
In the early works the IR-IR resonance and IR fluorescence techniques were used for determination of $\mathrm{V}-\mathrm{V}^{\prime}$ and $\mathrm{V}-\mathrm{T}$ rate constants of the processes in binary mixtures containing $\mathrm{SF}_{6}$ with low level of excitation, ${ }^{2,4,5}$ in these experiments vibrationally excited $\mathrm{SF}_{6}$ could be considered only as a small admixture in the "cold" gaseous buffer.

A few works on the relaxation of MPE $\mathrm{SF}_{6}$ molecules on "cold" $\mathrm{SF}_{6}$ molecules are available ${ }^{6-10}$ in which characteristic $\mathrm{V}-\mathrm{T}$ relaxation times were estimated. It has been proved by interferometry technique that at high energy of IR radiation the characteristic relaxation time for $\mathrm{MPE} \mathrm{SF}_{6}$ in pure $\mathrm{SF}_{6}$ and $\mathrm{SF}_{6}-\mathrm{Ar}$ mixtures is several times lower than for regime of weak excitation. ${ }^{9}$ There are practically no quantitative data on collision deactivation of MPE $\mathrm{SF}_{6}$ molecules on chemically inert gases as well as on the reactional molecules including the ozone molecules.

The dynamics of vibrational energy transfer from the MPE sensitizer $\left(\mathrm{SF}_{6}\right)$ to the other molecules of gaseous mixture may be observed not only by registration of the energy transformation of the sensitizer itself (e.g. by means of IR-IR, IR-UV resonance and IR luminescence) but by kinetics of excitation of the collision partners as well. In the present work an UV probing technique has been suggested for the kinetic study of excitation of the partner molecules $\left(\mathrm{O}_{3}\right)$ on collisions with $\mathrm{SF}_{6}$. The technique is based on the registration of the change in the UV spectrum of the ozone molecule in the region of Hartly band $(200-300 \mathrm{~nm})$ which is caused by the alteration of the extinction coefficient in the course of the transfer of vibrational energy into vibrational modes of ozone molecules $v_{1}$ and $v_{3}$ which manifest themselves in the UV absorption spectra. It has been shown that the extinction coefficient of ozone $\left(\varepsilon_{\lambda}\right)$ can be represented as follows: ${ }^{12}$

$$
\varepsilon_{\lambda}=\left(P_{000}+P_{010}\right) \varepsilon_{\lambda}^{000}+\left(P_{100}+P_{001}\right) \varepsilon_{\lambda}^{*}
$$

where $\varepsilon_{\lambda}^{000} \approx \varepsilon_{\lambda}^{010}$ is the extinction coefficient for the $\mathrm{O}_{3}(000)$ and $\mathrm{O}_{3}(010)$ states; $\varepsilon_{\lambda}^{*}$ is the mean weighted (according to population) extinction coefficient of the $\mathrm{O}_{3}(001)$ and $\mathrm{O}_{3}(100)$ states; $P_{000}, P_{100}, P_{010}, P_{001}$ are the relative populations of the corresponding vibrational states of the ground electronic term of ozone $\left({ }^{1} A_{1}\right)$. It is well known, that if $\lambda<271 \mathrm{~nm}$, the inequality $\varepsilon_{\lambda}{ }^{*}<\varepsilon_{\lambda}^{000}$ is true. For instance $\varepsilon_{\lambda}^{*} / \varepsilon_{\lambda}^{000}=0.17$ for $\lambda=254 \mathrm{~nm} .{ }^{12}$ The alteration of the optical density $(\Delta \mathrm{A})$ due to vibrationally excited ozone molecule $\left(\mathrm{O}_{3}^{\ddagger}\right)$ is related to the concentration of the latter by equation:

$$
\Delta A=\left[\mathrm{O}_{3}^{\ddagger}\right] l \Delta \varepsilon_{\lambda}
$$

where $\left[\mathrm{O}_{3}^{\ddagger}\right]=\left[\mathrm{O}_{3}(100)\right]+\left[\mathrm{O}_{3}(001)\right], l$ is the optical thickness of the absorbing gas layer (in $\mathrm{cm}$ ), $\Delta \varepsilon_{\lambda}=\varepsilon_{\lambda}{ }^{*}-\varepsilon_{\lambda}$. ${ }^{000} \mathrm{It}$ is evident from Eq. (2) that the time dependence of $\Delta A$ represent the temporal dependence of $\left[\mathrm{O}_{3}^{\ddagger}\right]$.

\section{EXPERIMENTAL}

The block diagram of the experimental setup for the study of the relaxation of MPE $\mathrm{SF}_{6}$ molecules in mixture with $\mathrm{O}_{3}$ is represent in Figure 1. Information on the 


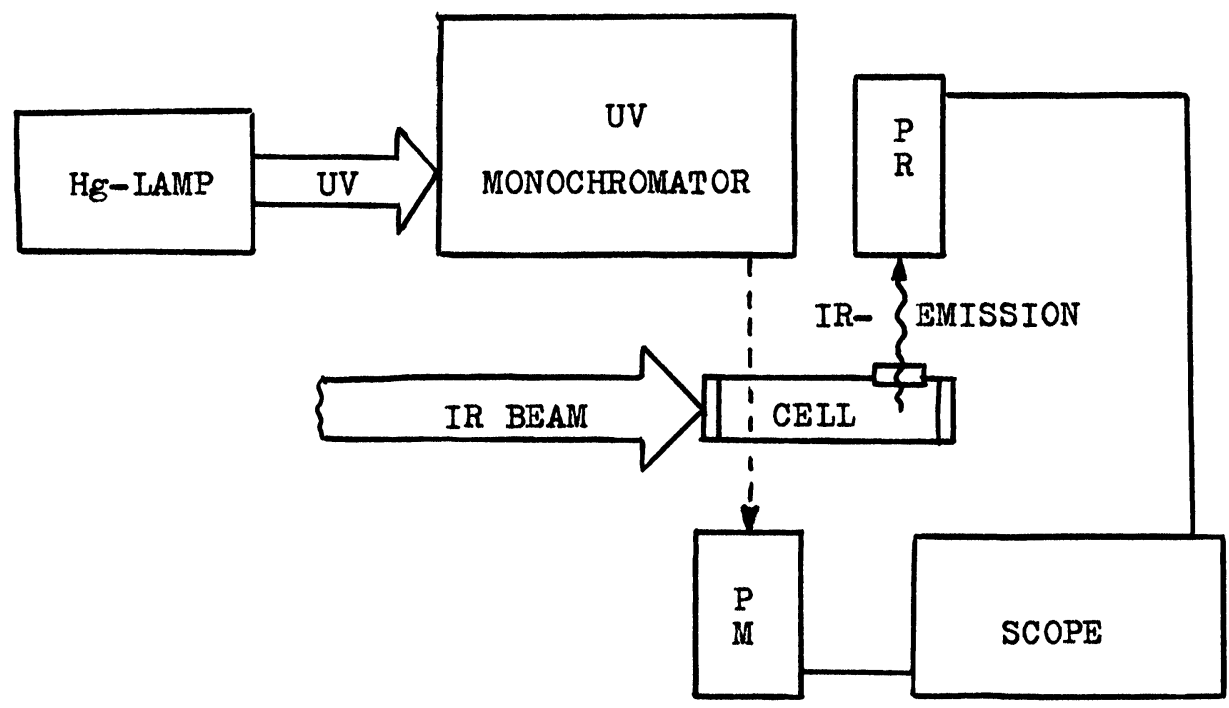

Figure 1 Block-scheme of experimental setup for investigation IR laser induced vibrational relaxation of MPE SF 6 molecules, PR-photoresistor Ge-Au (77 K), PM-photomultiplier.

dynamics of the vibrational relaxation of MPE molecules $\mathrm{SF}_{6}$ after the pulse of the IR radiation $\left(F=0.6 \mathrm{~J} / \mathrm{cm}^{2}, \tau_{1 / 2}=70 \mathrm{~ns}, \lambda=10.6 \mu \mathrm{m}\right)$ was obtained from the dependence of the intensity of the continuous UV radiation $(\lambda=253.6 \mathrm{~nm})-I(t)$, crossed the gas mixture. $I(t)=I^{o}+\Delta I(t)$, where $I^{o}$ is the constant component which was measured by a digital voltmeter and $\Delta I(t)$ is the variable component which was registered by oscilloscope. The experiment was carried out in a cylindrical quartz cell $18 \times 60 \mathrm{~mm}$ equipped with $\mathrm{BaF}_{2}$ windows. The gaseous mixture contained $\mathrm{SF}_{6}(0.6$ Torr) $\mathrm{O}_{3}$ (1-5 Torr), buffer gases $\mathrm{He}, \mathrm{Ar}, \mathrm{Kr}$ (0-5 Torr).

It is necessary to note, that in our experiments was completely excluded the direct vibrational excitation of ozone molecules by IR laser pulse in gas mixture. It was provided with considerable distance in IR absorption spectrum $\left(\sim 100 \mathrm{~cm}^{-1}\right)$ between vibrational mode $v_{3}$ of ozone, centered at $1042.1 \mathrm{~cm}^{-1}$ and vibrational mode $v_{3}$ of $\mathrm{SF}_{6}$, which was excited at $\omega=944.19 \mathrm{~cm}^{-1}$ laser line. The linewidths of these vibrational modes does not cover each other in linear IR spectrum. The absence of direct excitation of ozone molecules was confirmed in series of experiments, when irradiated gas mixture was not contained $\mathrm{SF}_{6}$ molecules. In that case there were not any obvious temporal changes in UV absorption of ozone after the laser shot, ${ }^{13 \mathrm{~m} 14}$ Moreover, we could not define in such conditions any absorption of IR laser beam in the cell.

\section{RESULTS AND DISCUSSION}

Figure 2 represents the initial part of the oscillogram with the $\Delta I(t)$ value changing from 0 to $\Delta I_{\max }$ for $20-30 \mu$ s after the completion of the IR pulse. 


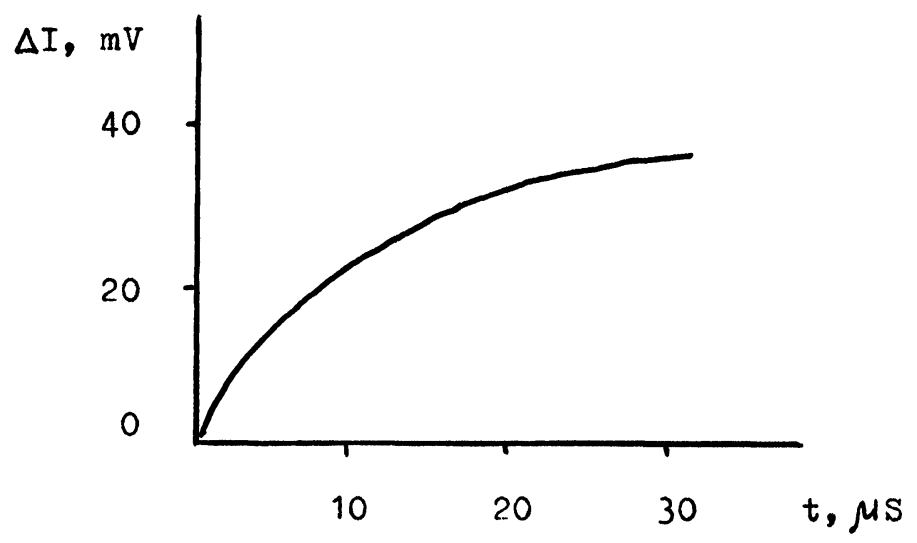

Figure 2 Picture of initial portion of detected UV transmission $(\lambda=253.6 \mathrm{~nm})$ through the gas cell, containing $\mathrm{SF}_{6}-\mathrm{O}_{3}-\mathrm{M}$ mixture, after laser shot, $\mathrm{SG}_{6}$ (0.6 Torr), $\mathrm{O}_{3}$ (1 Torr), $\mathrm{M}$ (0 Torr).

According to Eq. (2) and Lambert-Beer law:

$$
\Delta A=A(t)-A^{o}=\lg \left\{I_{0} /\left[I^{o}+\Delta I(t)\right]\right\}-\lg \left(I_{0} / I^{o}\right)
$$

where from taking into account that for all the experiments $\Delta I(t) \ll I^{o}$, one can get:

$$
\Delta I=\text { const } \cdot\left[\mathrm{O}_{3}^{\ddagger}\right] \cdot I^{o} \cdot \ell \cdot \Delta \varepsilon_{\lambda}
$$

The $\left[\mathrm{O}_{3}^{\ddagger}\right]$ and $\Delta I(t)$ are apparent to be given by one and the same time dependence.

We connect the dynamics of the $\left[\mathrm{O}_{3}^{\ddagger}\right]$ increase in the system with a simple collisional model of the relaxation. The excess of vibrational energy of the system after the IR laser exposure will be characterized by $\langle n\rangle$ - the mean number of quants $(\mathrm{h} \omega)$ absorbed by one $\mathrm{SF}_{6}$ molecule from the IR field. The determinated value of parameter $\langle n\rangle \simeq 8$ was still constant for all gas mixtures under investigation. It was controlled by accurate measurements of IR energy absorbed in the cell from laser beam by calorimetric detector with $5 \%$ error of absorbed energy. Thus we supposed, that the initial average energy of $\mathrm{SF}_{6}$ molecules after the laser shoot does not change with the addition of small amounts of ozone and buffer gases in whole series of our experiments.

For a two component mixture $\mathrm{O}_{3}-\mathrm{SF}_{6}$ the relaxation of $\mathrm{MPE} \mathrm{SF}_{6}$ in the scope of such model may be considered as a uniquantum $\mathrm{V}-\mathrm{V}^{\prime}$ energy transfer process from MPE SF 6 to $\mathrm{O}_{3}(000)$ with the formation of the $\mathrm{O}_{3}(100)$ and $\mathrm{O}_{3}(001)$ states and also a parallel $\mathrm{V}-\mathrm{T}$ relaxation channel. A schematic representation is as follows:

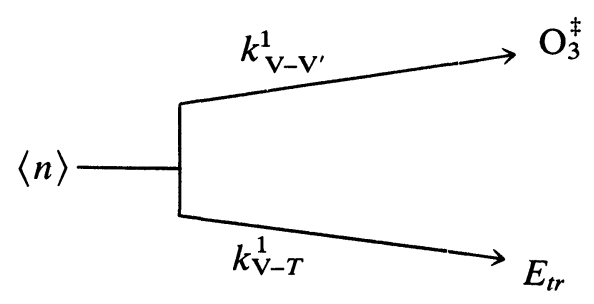


To a first approximation this process may be described by a kinetic scheme of two parallel processes with the first order rate constants $k_{\mathrm{V}-\mathrm{V}^{\prime}}^{1}$ and $k_{\mathrm{V}-\mathrm{T}}^{1}$.

It is obvious, that the experimental data of $\langle n\rangle$ produce no information about the initial shape of vibrational energy distribution of $\mathrm{SF}_{6}$ molecules after the excitation by high-power IR laser field. The detailed investigation of multiphoton excitation demonstrates the existence of two groups of $\mathrm{SF}_{6}$ molecules: the "hot" ensemble disposed in quasi-continuum, and the "cold" ensemble, which includes some molecules located on the low vibrational levels and in the ground state. ${ }^{15}$ The first step in the temporal process of vibrational energy transfer in $\mathrm{MPE} \mathrm{SF}_{6}$ is the very first fast $\mathrm{V}-\mathrm{V}$ and $\mathrm{V}-\mathrm{V}^{\prime}$ energy exchange among these two groups, which lead to produce single Boltzman distribution between vibrational degrees of freedom in $\mathrm{SF}_{6}$ gas with very high initial vibrational temperature $\left(T_{\text {vib }}=1500 \div 1600 \mathrm{~K}\right.$ in our case $)$. The characteristic time of such fast process for $\mathrm{SF}_{6}$ molecules was estimated ${ }^{16}$ ( $p \tau=1 \mu \mathrm{s} \cdot$ Torr). The technique of UV probing allowed us to detect only the further process of vibrational energy transfer from $\mathrm{SF}_{6}$ molecules to $\mathrm{O}_{3}$, lowering the vibrational temperature of $\mathrm{SF}_{6}$ and exciting ozone. We consider, that this process is more complicated and occurs in collisions according to kinetic scheme $\left(^{*}\right)$. Finally, such relaxation kinetics results in equal value of vibrational temperature of all components and translational temperature of the gas, so, at last the mixture in the cell becomes completely thermolizated at equilibrium value of temperature.

This scheme is supported by a series of different considerations. First, of all the relaxation of MPE $\mathrm{SF}_{6}$ occurs in the medium of excess of "cold" ozone $\mathrm{O}_{3}(000)$. Alongside with uniquantum excited states $\mathrm{O}_{3}(001)$ and $\mathrm{O}_{3}(100)$ the multiquantum energy tranfer is possible to produce the $\mathrm{O}_{3}(00 \mathrm{~K})$ and $\mathrm{O}_{3}(N 00)$ states. However, on collisions with $\mathrm{O}_{3}(000)$ molecules the "hot" ozone molecules will quickly lose their energy in quasi-resonance uniquantum $\mathrm{V}-\mathrm{V}^{\prime}$ processes, thus transferring to $\mathrm{O}_{3}(100)$ and $\mathrm{O}_{3}(001)$ states manifesting themselves in the UV absorption spectra of ozone. The energy transfer from MPE SF 6 into the $v_{2}$ mode of ozone molecule gives no alteration in the ozone spectrum, however the transfer from the $v_{2}$ mode of ozone molecule to the $\mathrm{O}_{3}(100)$ and $\mathrm{O}_{3}(001)$ levels will contribute to the change of optical transmission in the UV range of the absorption spectrum of $\mathrm{O}_{3}$. Thus the $k_{\mathrm{V}-\mathrm{V}^{\prime}}^{1}$ is the bottom limit of the specific rate of the vibrational energy transfer from $\mathrm{SF}_{6}$ molecules to $\mathrm{O}_{3}$. The $\mathrm{V}-\mathrm{V}^{\prime}$ intermolecular exchange between $\mathrm{SF}_{6}$ molecules does not change substantially vibrational energy of $\mathrm{SF}_{6}$ molecules as a whole ensemble and consequently cannot be considered as an effective decay of vibrational energy of MPE SF 6 . Only a small part of vibrational energy can be transferred into the translation as a result of the energy defects in the course of intermode transformations in $\mathrm{SF}_{6}$. That is why the $\mathrm{V}-\mathrm{T}$ relaxation process from the lower vibrational levels $\mathrm{SF}_{6}$ with the rate constant $k_{\mathrm{V}-\mathrm{T}}^{1}$ is the lowest limit of the rate transformation of vibrational energy from $\mathrm{MPE} \mathrm{SF}_{6}$ into translation. On the other hand, the $\mathrm{V}-\mathrm{T}$ relaxation process of MPE $\mathrm{SF}_{6}$ should not effect greatly the $\mathrm{O}_{3}^{\ddagger}$ concentration, because in conformity with the principle of detailed equilibrium, the $\mathrm{O}_{3}$ excitation as a result of $\mathrm{T}-\mathrm{V}$ process occurs considerably slower than the $\mathrm{V}-\mathrm{T}$ process for $\mathrm{O}_{3}^{\neq}$, occurs according to work ${ }^{17}$ from the $v_{2}$ mode of molecule $\mathrm{O}_{3}(010)$ with the rate constant $k_{\mathrm{V}-\mathrm{T}}=1.0110^{-13} \mathrm{~cm}^{3} / \mathrm{s}$. Thus 
in the time scale under investigation $(20-30 \mu \mathrm{s})$ the $\mathrm{T}-\mathrm{V}$ excitation process of $\mathrm{O}_{3}$ can be neglected.

Kinetics of $\mathrm{O}_{3}^{\ddagger}$ formation according to the scheme $\left({ }^{*}\right)$ can be expressed as follows:

$$
\left[\mathrm{O}_{3}^{\ddagger}\right](t)=\langle n\rangle\left[\mathrm{SF}_{6}\right] \frac{k_{\mathrm{V}^{-} \mathrm{V}^{\prime}}^{1}}{k_{\mathrm{V}^{-} \mathrm{V}^{\prime}}^{1}+k_{\mathrm{V}-\mathrm{T}}^{1}}\left\{1-\exp \left[-\left(k_{\mathrm{V}^{-\mathrm{V}^{\prime}}}^{1}+k_{\mathrm{V}-\mathrm{T}}^{1}\right) t\right]\right\}
$$

where $k_{\mathrm{V}-\mathrm{T}}^{1}=k_{\mathrm{V}_{-\mathrm{T}}}^{\mathrm{SF}_{6}-\mathrm{SF}_{6}}\left[\mathrm{SF}_{6}\right], k_{\mathrm{V}_{-} \mathrm{V}^{\prime}}^{1}=k_{\mathrm{V}_{-} \mathrm{V}^{\prime}}^{\mathrm{SF}_{6}-\mathrm{O}_{3}}\left[\mathrm{O}_{3}\right]$ and $k \underset{\mathrm{V}_{-} \mathrm{V}^{\prime}}{\mathrm{SF}_{6}-\mathrm{O}_{3}}$-is the effective rate constant of the vibrational relaxation $\mathrm{SF}_{6}$ on ozone molecules, $k_{\mathrm{V}-\mathrm{T}}^{\mathrm{SF}_{6}-\mathrm{SF}_{6}}$-is an effective rate constant of $\mathrm{SF}_{6}$ vibrational self-relaxation. The value

$$
\langle n\rangle\left[\mathrm{SF}_{6}\right] \frac{k_{{\mathrm{V}-\mathrm{V}^{\prime}}^{1}}^{1}}{k_{\mathrm{V}-\mathrm{V}^{\prime}}^{1}+k_{\mathrm{V}-\mathrm{T}}^{1}}
$$

is the top concentration of the vibrationally excited ozone $\left(\left[\mathrm{O}_{3}^{\ddagger}\right]_{\max }\right)$ which can be achieved by the completion of relaxation of MPE $\mathrm{SF}_{6}$. In accordance with Eq. (4) $\left[\mathrm{O}_{3}^{\ddagger}\right]_{\max }$ corresponds to the $\Delta I_{\max }$ value on the oscilloscope record. Combining the Eq. (4) and (5) one can get:

$$
\Delta I(t)=\Delta I_{\max }\left\{1-\exp \left(-k_{\Sigma}^{1} t\right)\right\}
$$

where

$$
k_{\Sigma}^{1}=k_{\mathrm{V}^{-} \mathrm{V}^{\prime}}^{\mathrm{SF}^{\prime} \mathrm{O}_{3}}\left[\mathrm{O}_{3}\right]+k_{\mathrm{V}_{-} \mathrm{T}}^{\mathrm{SF}_{6}-\mathrm{SF}_{6}}\left[\mathrm{SF}_{6}\right]
$$

It is obvious from (7), that at $\left[\mathrm{SF}_{6}\right]=$ const. the $k_{\Sigma}^{1}$ values calculated from the experimental data according to (6) change linearly with $\left[\mathrm{O}_{3}\right]$ changes. Figure 3

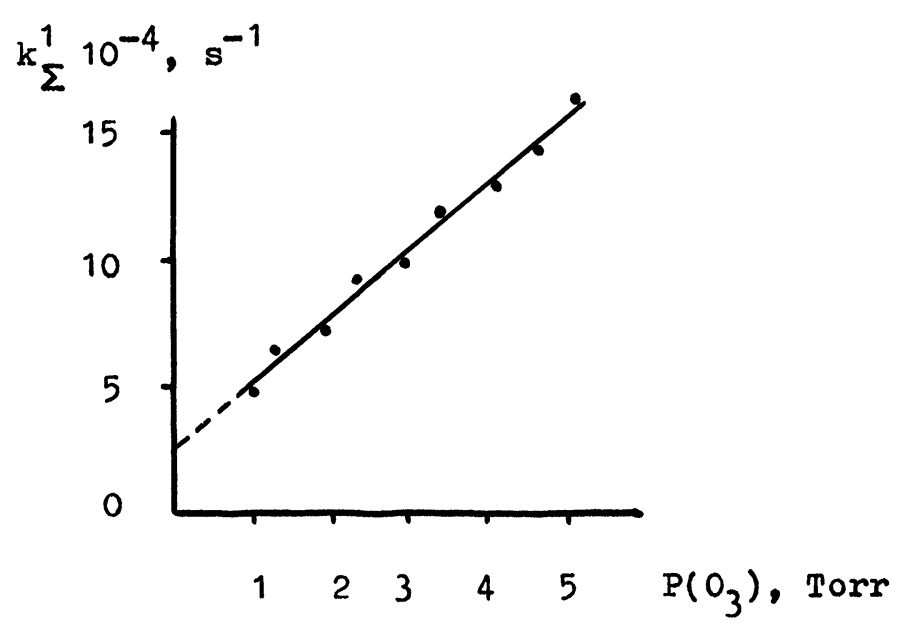

Figure 3 Rise of effective rate constant $\left(k_{\Sigma}^{1}\right)$ of vibrational relaxation of $\mathrm{MPE} \mathrm{SF}_{6}$ molecules in $\mathrm{SF}_{6}-\mathrm{O}_{3}$ mixtures versus $\mathrm{O}_{3}$ pressure, $\mathrm{SF}_{6}(0.6$ Torr). 
demonstrates that the $k_{\Sigma}^{1}$ values vary in direct proportion to the ozone partial pressure. The slope of the corresponding experimental points gives for the constant $k_{\mathrm{V}-\mathrm{V}^{\prime}}$ the value of $7.710^{-13} \mathrm{~cm}^{3} / \mathrm{s}(p \tau=40 \mu \mathrm{s}$ Torr). Extrapolation of the slope to zero value of ozone pressure gives the value of $(4.8 \div 6.4) 10^{-13} \mathrm{~cm}^{3} / \mathrm{s}(p \tau=49 \div 65$ $\mu \mathrm{s}$. Torr) for $k_{\mathrm{V}-\mathrm{T}}^{\mathrm{SF}_{6}-\mathrm{SF}_{6}}$.

The same procedure was applied for the calculations of relaxation rate constants for the $\mathrm{O}_{3}-\mathrm{SF}_{6}$ systems with added buffer gases. One more $\mathrm{V}-\mathrm{T}$ relaxation channel of $\mathrm{MPE} \mathrm{SF}_{6}$ on the buffer molecules appears. It means that one more component $k_{\mathrm{V}-\mathrm{T}}^{\mathrm{SF}_{6}-\mathrm{O}_{3}}[\mathrm{M}]$ enters into the equation for $k_{\Sigma}^{1}$. Varying the content of the buffer gas in the system with constant $\left[\mathrm{SF}_{6}\right]$ and $\left[\mathrm{O}_{3}\right]$ one can obtain a linear correlation $k_{\Sigma}^{1}$ with $[\mathrm{M}]$, which is represented in Figure 4. The relaxation rate constants of $\mathrm{MPE} \mathrm{SF}_{6}$ on $\mathrm{He}$, $\mathrm{Ar}, \mathrm{Kr}$ molecules obtained from these data come to $k_{\mathrm{V}-\mathrm{T}}^{\mathrm{SF}_{6}-\mathrm{He}}=3.110^{-13} \mathrm{~cm}^{3} / \mathrm{s}$, $k_{\mathrm{V}-\mathrm{T}}^{\mathrm{SF}_{6}-\mathrm{Ar}}=2.310^{-13} \mathrm{~cm}^{3} / \mathrm{s}, k_{\mathrm{V}-\mathrm{T}}^{\mathrm{SF}_{6}-\mathrm{Kr}}=7.710^{-14} \mathrm{~cm}^{3} / \mathrm{s}$ respectively.

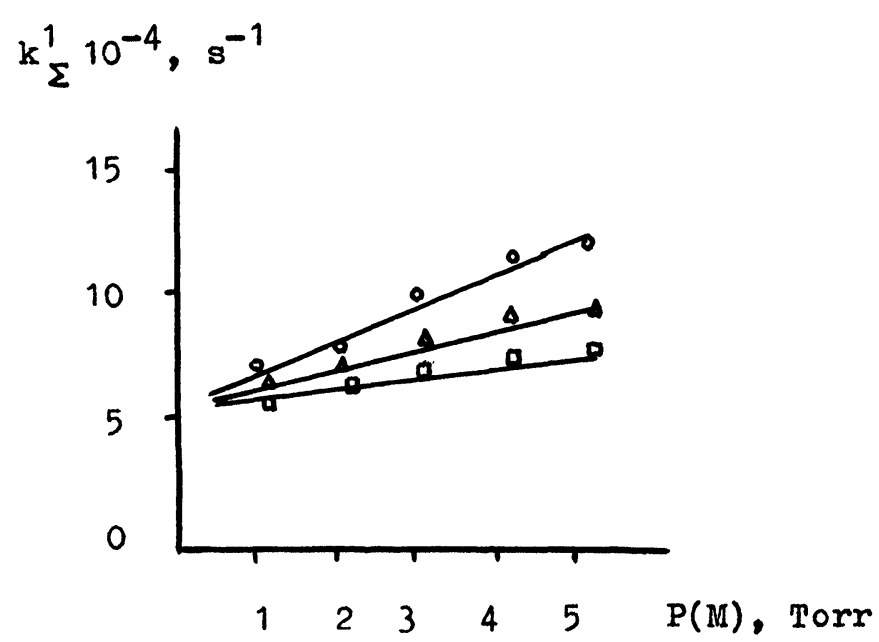

Figure 4 Rise of effective rate constant $\left(k_{\Sigma}^{1}\right)$ of vibrational relaxation of MPE SF 6 molecules in $\mathrm{SF}_{6}-\mathrm{O}_{3}-\mathrm{M}$ mixtures $(\mathrm{M}=\mathrm{He}, \mathrm{Ar}, \mathrm{Kr})$ versus inert gas pressure, $\mathrm{SF}_{6}(0.6 \mathrm{Torr}), \mathrm{O}_{3}(2 \mathrm{Torr}), \mathrm{O}-\mathrm{He}$, $\Delta-\mathrm{Ar}, \square-\mathrm{Kr}$.

An investigation of $\mathrm{V}-\mathrm{T}$ relaxation of $\mathrm{MPE} \mathrm{SF}_{6}$ in mixtures with $\mathrm{Kr}$ by direct method of IR luminescence quenching ${ }^{4}$ in the region of $\lambda=6.3 \mu \mathrm{m}$ was carried out in order to estimate the reliability of the data obtained in the present study by UV probing. IR emission was registered by a photodetector $\mathrm{Ge}-\mathrm{Au}(77 \mathrm{~K})$ and attributed to the vibrational transfer in MPE SF 6 from the combination $v_{2}+v_{3}$ levels to the ground state and $v_{2}+v_{3}+v_{6} \rightarrow v_{6}{ }^{18}$ The temporal decay of the IR luminescence intensity represented in Figure 5 can be adequately approximated by the exponential function such as:

$$
I_{f}=I_{f}^{o} \exp (-t / \tau)
$$

where $I_{f}^{o}$ is the IR luminescence signal in maximum, $\tau$ is the characteristic time of 


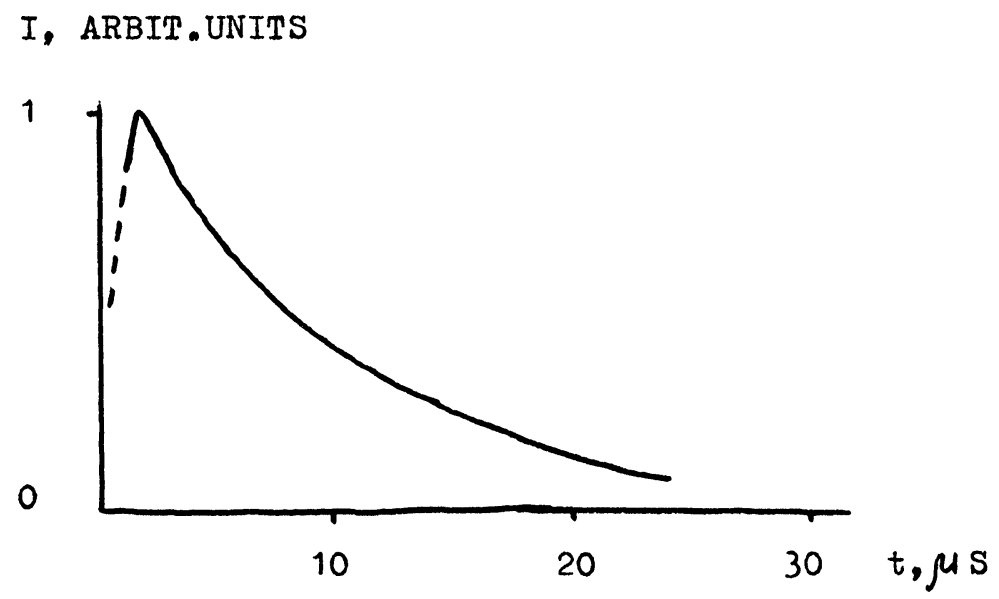

Figure 5 Temporal profile of decay IR flourescence of $\mathrm{MPE} \mathrm{SF}_{6}$ molecules at $\lambda=6.3 \mu \mathrm{m}$ in $\mathrm{SF}_{6}-\mathrm{Kr}$ mixture, $\mathrm{SF}_{6}$ (1 Torr), $\mathrm{Kr}$ (20 Torr).

$\dot{V}-\mathrm{T}$ relaxation in the gaseous mixture $\mathrm{SF}_{6}-\mathrm{Kr}$ under investigation. It has been shown that in $\mathrm{SF}_{6}$ mixtures with inert gases the parameter $\tau$ is given by the equation:

$$
(\tau)^{-1}=k_{\mathrm{V}_{-} \mathrm{T}}^{\mathrm{SF}_{6}-\mathrm{SF}_{6}}\left[\mathrm{SF}_{6}\right]+k_{\mathrm{V}-\mathrm{T}}^{\mathrm{SF}_{6}-\mathrm{Kr}}[\mathrm{Kr}]
$$

where $k_{\mathrm{V}-\mathrm{T}}^{\mathrm{SF}}$ is the rate constant of $\mathrm{V}-\mathrm{T}$ relaxation of MPE $\mathrm{SF}_{6}$ on $\mathrm{Kr}$.

As may be inferred from (9) at $\left[\mathrm{SF}_{6}\right]=$ const. the $(\tau)^{-1}$ values should depend linearly from the $[\mathrm{Kr}$,$] . The experimental data are given in the Figure 6$ in $(\tau)^{-1}-[\mathrm{Kr}]$

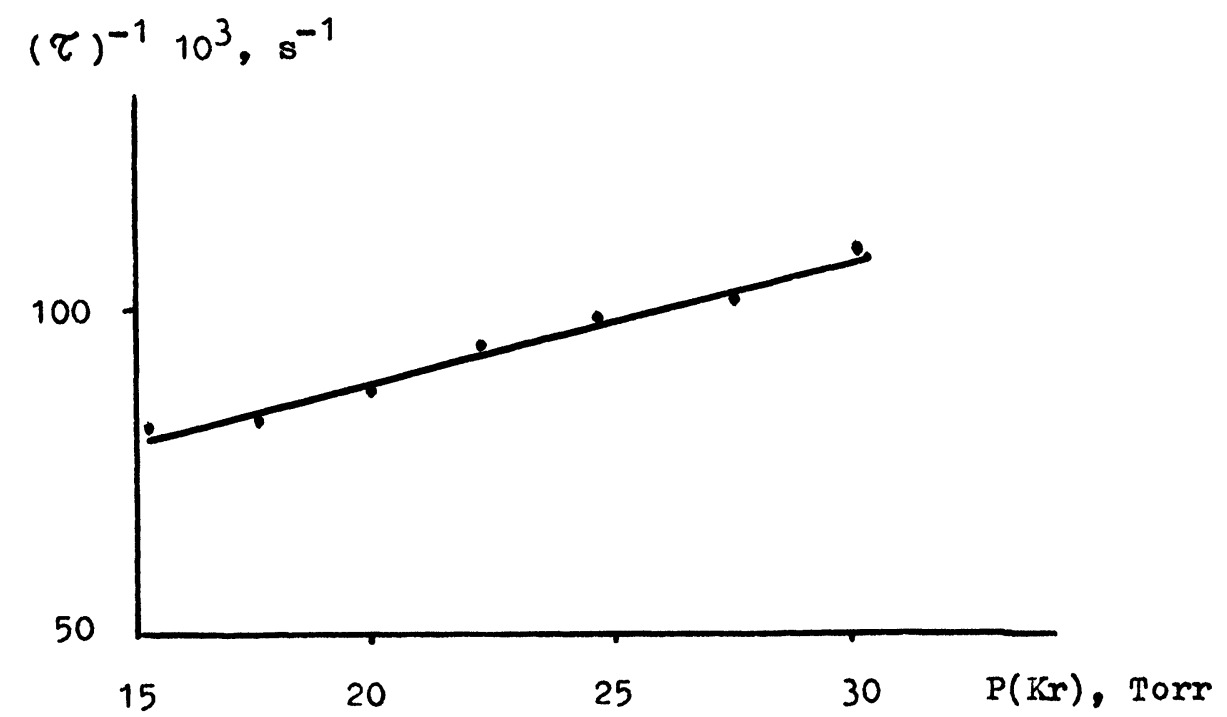

Figure 6 Rise of inverse characteristic time of $\mathrm{V}-\mathrm{T}$ relaxation $\left(\tau_{\mathrm{V}-\mathrm{T}}\right)^{-1}$ of $\mathrm{MPE} \mathrm{SF}_{6}$ molecules in $\mathrm{SF}_{6}-\mathrm{Kr}$ mixtures versus $\mathrm{Kr}$ pressure, $\mathrm{SF}_{6}$ (1 Torr). 
coordinates. The value $k_{\mathrm{V}-\mathrm{T}}^{\mathrm{S} \mathrm{F}_{6}-\mathrm{Kr}}=7.810^{-14} \mathrm{~cm}^{3} / \mathrm{s}$ was obtained from the slope of the experimental data. Extrapolation of the slope to the zero pressure of $\mathrm{Kr}$ gives the value of $k_{\mathrm{V}-\mathrm{T}^{\prime}}^{\mathrm{SF}_{6}-\mathrm{SF}_{6}}=1.010^{-12} \mathrm{~cm}^{3} / \mathrm{s}$.

It is worthwhile to note good agreement between the values of the effective rate constants of $\mathrm{V}-\mathrm{T}$ relaxation of $\mathrm{MPE} \mathrm{SF}_{6}$ molecules on the $\mathrm{Kr}$ molecules obtained by different methods. The corresponding values for the effective rate constants of vibrational self-relaxation of MPE $\mathrm{SF}_{6}$ are in good agreement as well.

The rate constants of $\mathrm{V}-\mathrm{V}^{\prime}$ and $\mathrm{V}-\mathrm{T}$ relaxational processes obtained in our work exceed in several times similar rate constants determined for one-photon excitation of $\mathrm{SF}_{6}$ molecules. ${ }^{2}$ This fact is in good agreement with the conclusion of considerable acceleration of relaxational kinetics for MPE SF 6 molecules. ${ }^{9}{ }^{910} \mathrm{But}$, in both regimes of high and weak excitation of $\mathrm{SF}_{6}$ molecules $\mathrm{V}-\mathrm{T}$ relaxational rate constants exhibit the same dependence on the mass of collisional partner in the file of $\mathrm{He}, \mathrm{Ar}, \mathrm{Kr}$. This dependence is well predicted in SSH theory ${ }^{19}$ by breathing-sphere approximation ${ }^{20,21}$ shows, that the rate constant of $\mathrm{V}-\mathrm{T}$ process becomes lower with increasing the mass of collisional partner.

\section{References}

1. W. M. Shaub and S. H. Bauer, Inter. J. Chem. Kinet., 7, 509 (1975).

2. J. I. Steinfield, I. Burak, D. G. Sutton and A. V. Novac, J. Chem. Phys., 52, 5421 (1970).

3. K. S. Ruthkovsky and K. G. Tokhadze, JETP, 75, 408 (1978).

4. R. D. Bates, J. T. Knudson, G. W. Flynn and A. M. Ronn, Chem. Phys. Lett., 8, 103 (1971).

5. R. D. Bates, J. T. Knudson and G. W. Flynn, J. Chem. Phys., 57, 4174 (1972).

6. S. A. Akhmanov, V. M. Gordienko, A. V. Mikheenko and V.Ya. Panchenko, JETP Lett., 26, 603 (1977).

7. S. A. Akhmanov, V. M. Gordienko, V. Ya. Panchenko, Izv. Vuzov, (Fizika), 11, 14 (1977).

8. S. A. Akhmanov, V. M. Gordienko, V. V. Lasarev, A. V. Mikheenko, V. Ya. Panchenko, Izv. AN SSSR, (ser. Fiz.), 43, 379 (1979).

9. S. A. Akhmanov, V. M. Gordienko, V. V. Lasarev, A. V. Mikheenko, V. Ya. Panchenko, JETP, 78, 2171 (1980).

10. R. Bruzzese, C. d'Ambrosio, S. Solimento, Infrared Phys., 25, 227 (1985).

11. A. V. Eletsky, V. D. Klimov and T. A. Udalova, JETP, 80, 558 (1981).

12. S. M. Adler-Golden, E. L. Schweitzer and J. I. Steinfeld, J. Chem. Phys., 76, 2201 (1982).

13. I. C. McDade and W. D. McGrath, Chem. Phys. Lett., 72, 432 (1980).

14. S. M. Adler-Golden and J. I. Steinfeld, Chem. Phys. Lett., 76, 479 (1980).

15. V. N. Bagratashvili, V. S. Doljikov and V. S. Letokhov, JETP, 76, 18 (1979).

16. S. S. Alimpiev, A. A. Mokhnatiuk, B. G. Sartakov, V. V. Smirnov and V. I. Fabelinsky, JETP Lett., 46, 380 (19870.

17. K. Hui, D. Rosen and T. Cool, Chem. Phys. Lett., 32, 141 (1975).

18. R. S. McDowell, J. P. Aldridge and R. F. Holland, J. Phys. Chem., 80, 1203 (1976).

19. R. N. Schwartz, Z. I. Slawsky and K. F. Herzfeld, J. Chem. Phys., 20, 1591 (1952).

20. F. I. Tanczos, J. Chem. Phys., 25, 439 (1956).

21. J. T. Yardley, C. B. Moore, J. Chem. Phys., 46, 4491 (1967). 